\title{
Lithium in drinking water and crime rates in Japan: cross-sectional study
}

\author{
Kentaro Kohno, Nobuyoshi Ishii, Hirofumi Hirakawa and Takeshi Terao
}

\section{Background}

In pharmacological doses, lithium successfully treats bipolar disorder and it can reduce violent crimes committed by individuals with this disorder.

\begin{abstract}
Aims
To investigate whether naturally occurring lithium in drinking water lowers rates of violent crime in the general population.
\end{abstract}

\section{Method}

We examined lithium levels in the drinking water of the 274 municipalities of Kyushu Island in Japan and compared these with the crime rates in each municipality.

\section{Results}

We found that lithium levels were significantly and inversely associated with crime rates in 2009.

\section{Conclusions}

Our findings suggest that even very low levels of lithium in drinking water may play a role in reducing crime rates in the general population.

\section{Keywords}

Lithium; trace element; drinking water; crime; epidemiological study.

\section{Copyright and usage}

(c) The Authors 2020. Published by Cambridge University Press on behalf of the Royal College of Psychiatrists. This is an Open Access article, distributed under the terms of the Creative Commons Attribution licence (http://creativecommons.org/ licenses/by/4.0/), which permits unrestricted re-use, distribution, and reproduction in any medium, provided the original work is properly cited.
Lithium is a soft, silvery white alkali metal that occurs naturally in foods (such as grains and vegetables). Significant amounts may also occur in drinking water. Research shows that it is probably essential to human health and it has been suggested that a $70 \mathrm{~kg}$ adult should aim for a dietary intake of $1000 \mu \mathrm{g} /$ day.

Generally accepted as a first-line treatment for bipolar disorder, lithium is also thought to be one of the best augmenting therapies for treatment-resistant depression. ${ }^{2}$ Meta-analysis of randomised controlled trials ${ }^{2}$ found lithium to be significantly more effective than placebo in reducing the number of suicides and all-cause mortality in the long-term treatment of mood disorders. Meta-analysis ${ }^{4}$ also suggests that lithium therapy can improve cognitive performance in mild cognitive impairment and Alzheimer's disease. Finally, a meta-analysis ${ }^{5}$ showed that lithium was significantly better than placebo in treating aggression. Thus, lithium is a very useful psychotropic medication.

A number of studies, mostly from the past decade, have investigated the effects of very small amounts of lithium in treating suicidality $^{6-10}$ and dementia ${ }^{11,12}$ and in modifying temperament ${ }^{13,14}$ and criminal behaviour. ${ }^{6,15-17}$ They suggest that trace lithium might be an effective prophylaxis for various psychiatric conditions, but randomised controlled trials are needed to enable definite conclusions to be drawn. The use of trace lithium to treat conditions such as dementia or to modify temperament or criminal behavioural is supported by very limited evidence and its effects are yet to be confirmed. ${ }^{2}$

This paper is part of a study of various potential effects of lithium in drinking water on a large population in Japan. ${ }^{7,8}$ Here we report on the association between lithium levels and crime rates in each of the municipalities of Kyushu Island, Japan.

\section{Method}

\section{Study population}

Kyushu Island is the southernmost of Japan's four large islands. In 2009, the total population of Kyushu Island was 14684 991. Kyushu
Island has 118 cities, 119 towns and 37 villages, totalling 274 municipalities. Of the 274 municipalities, Fukuoka City had the largest population (1 384820 residents) and Mishima village had the smallest (368 residents). This large difference in population was reflected across all 274 municipalities. ${ }^{8}$ These data were acquired from the Ministry of Internal Affairs and Communications, Tokyo, Japan. We assert that all procedures contributing to this work comply with the ethical standards of the relevant national and institutional committees on human experimentation and with the Helsinki Declaration of 1975, as revised in 2008.

\section{Measurement of lithium levels in drinking water}

Between 2010 and 2013, 434 drinking water samples were taken in the 274 municipalities (mainly from the main railway station or the municipal offices) and their lithium levels were measured by a third party using mass spectroscopy. This method can measure lithium levels as low as 0.1 parts per billion $(0.1 \mu \mathrm{g} / \mathrm{L})$. Where samples were taken at multiple points in the same municipality, the mean value was calculated. Although only single samples were taken at each location, resampling in the same places 1 year later confirmed that there was very little fluctuation in levels (correlation coefficient: 0.998). ${ }^{8}$

\section{Crime rates}

The criminal offences evaluated included homicide, rape, robbery, arson, violence, fraud and gambling, but excluded negligence resulting in traffic accidents. Crime rates were calculated by dividing the number of recognised criminal offences by the total populations per municipality in 2009, because crime data have not been published since then.

\section{Adjustment factors}

We first generated a crude model of the association between lithium levels in drinking water and crime rates, without adjusting for confounding factors (crude model). We then studied the associations in 
more detail by adjusting for the proportion of 1-person households, ${ }^{18}$ the overall unemployment rate ${ }^{19}$ and the proportion of elderly people ${ }^{20}$ (adjusted model). These data were available for 2010 for all 274 municipalities (from the Statistics Bureau, Ministry of Internal Affairs and Communications).

\section{Statistical analysis}

Treating all data equally would give less precisely measured data points more influence than they merit and highly precise data points too little influence. We therefore performed a weighted least squares regression analysis in an attempt to give each data point its proper influence over the parameter estimates. To allow for the great differences in population size across the 274 municipalities, we also used weighted least squares regression analysis adjusted for the size of each population. ${ }^{8}$ We used multiple regression analyses to calculate crime rates in 2009 from lithium levels and the adjustment factors in 2010.

\section{Results}

\section{Lithium levels}

Figure 1 shows the lithium levels in the drinking water across Kyushu Island's 274 municipalities from 2010 to 2013. The mean level was $4.2 \mu \mathrm{g} / \mathrm{L}$ (s.d. = 9.3; range $0-130$ ).

\section{Crime data}

The National Police Agency recognised 166056 criminal offences across Kyushu Island in 2009 (from the Statistics Bureau, Ministry of Internal Affairs and Communications). ${ }^{21}$ Figure 2 shows the crime rates across Kyushu Island's 274 municipalities. The mean crime rate was $1.13 \%$.

\section{Adjustment factors}

In 2010, the mean proportion of 1-person households in 2010 was $27.2 \%$ (s.d. $=7.6$; range 14.4-61.6). The mean overall unemployment rate was $7.5 \%$ (s.d. $=2.9$; range $0.8-20.3$ ). The mean proportion of elderly people was $27.7 \%$ (s.d. $=6.4$; range $14.0-43.4$ ). ${ }^{8}$

\section{Association between crime rates and lithium levels}

As shown in Table 1, we found no association between lithium levels in drinking water and crime rates in the crude model. However, lithium levels were significantly and inversely associated with crime rates after adjusting for the proportion of elderly people, the proportion of 1-person households and the overall unemployment rate (adjusted model). There was no multicollinearity in the multiple regression analyses.

\section{Discussion}

It has been suggested that high impulsivity is a risk factor for criminal involvement, ${ }^{22}$ and both animal and human studies have examined the effects of lithium on impulsivity. Ohmura et al ${ }^{23}$ reported that lithium (but not valproate or carbamazepine) suppressed impulsive actions in rats, and Halcomb et al ${ }^{24}$ reported that lithium (but not valproate) reduced impulsive choice in the delaydiscounting task in mice. Moreover, lithium decreases levels of impulsivity as measured by various outcome measures not only in individuals with bipolar disorder but also in those with other impulse control disorders. ${ }^{5,25}$

As far as we know, the first evidence that trace amounts of lithium in tap water might affect mental health appeared in 1972, when Dawson et al reported that psychiatric hospital admissions and homicide rates were lower in Texas counties with higher lithium levels in the water supply. ${ }^{15}$ In 1990, Schrauzer \& Shrestha ${ }^{6}$ published a study examining the association between
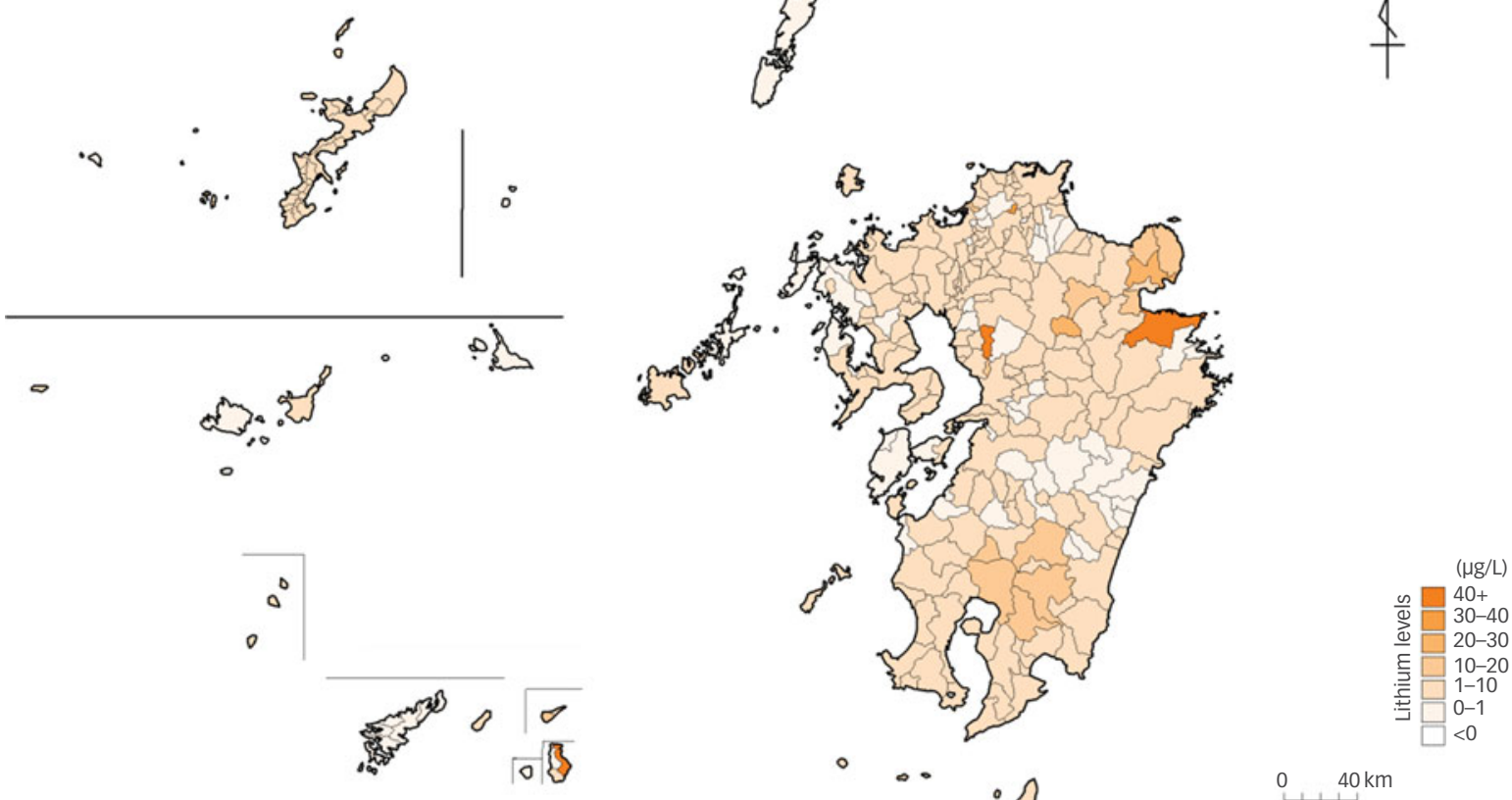

Fig. 1 Lithium levels in drinking water across the 274 municipalities of Kyushu Island, Japan (2010-2013). 


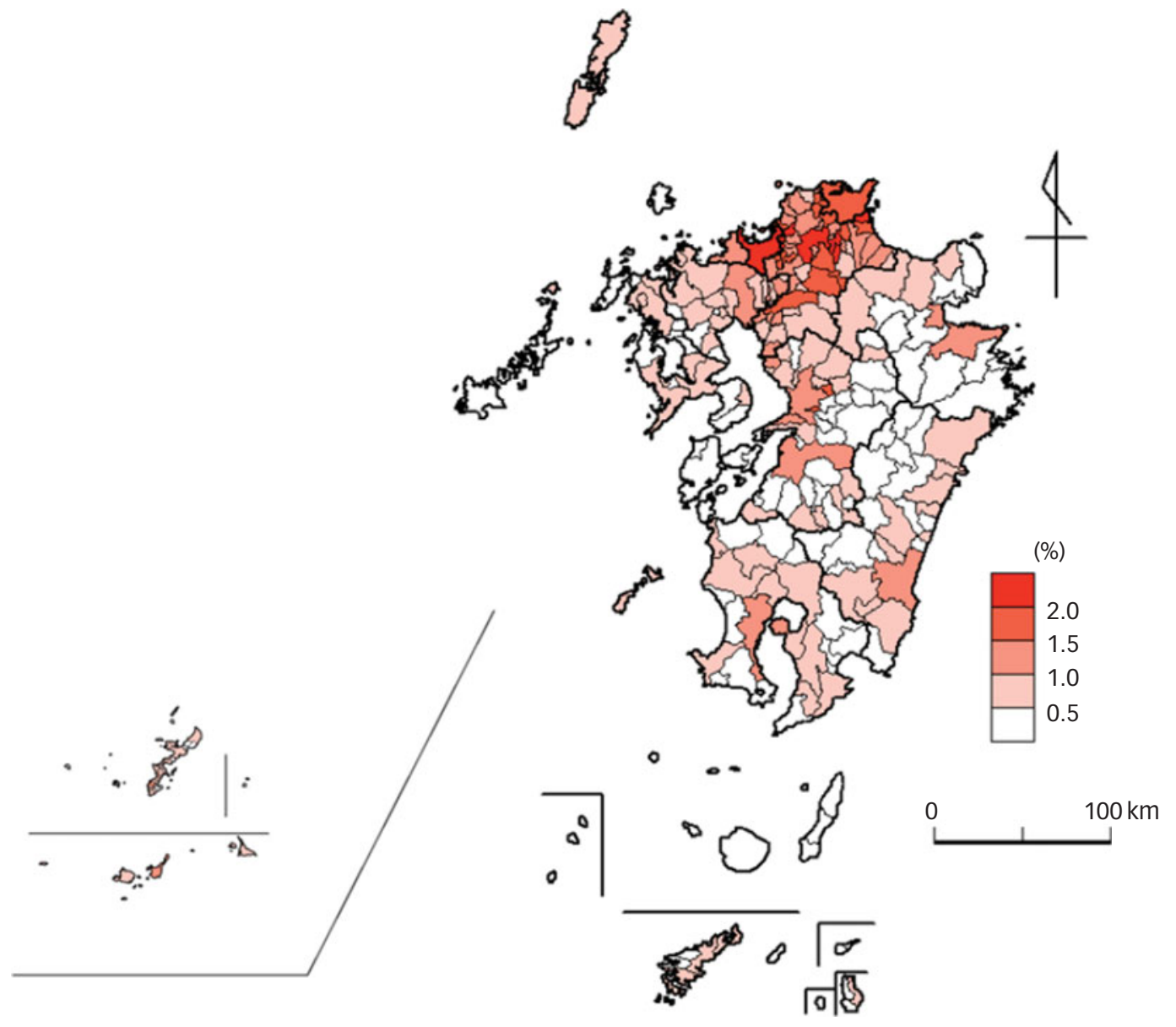

Fig. 2 Crime rates across the 274 municipalities of Kyushu Island, Japan (2009).

lithium in drinking water and crime, suicide and drug-related arrests, again based in Texas. Water samples were taken in 27 Texas counties between 1978 and 1987. The mean annual incidence rates of homicide, suicide, rape, robbery, burglary, theft and total crime over the sampling period were significantly higher in counties with low lithium levels (mean $5 \mu \mathrm{g} / \mathrm{L}$; s.d. $=4$; range $0-12$ ) than in those with high levels (mean $123 \mu \mathrm{g} / \mathrm{L}$; s.d. $=25$; range $70-160$ ); all differences except those for assault were statistically significant $(P<0.01)$. The authors concluded that their results suggest that lithium at levels that may be encountered in public water supplies has moderating effects on suicidal and violent criminal behaviour. They subsequently reported that lithium levels in scalp hair are low in incarcerated violent criminals. ${ }^{16}$ In Greece, Giotakos et al ${ }^{17}$ reported that the mean number of homicides tended to be lower in prefectures with high levels of lithium in the water supply $\left(R^{2}=0.054, \beta=-0.38, P=0.004\right)$. Ando et al ${ }^{26}$ investigated the

Table 1 Crime rates and lithium levels in drinking water (274 municipalities of Kyushu Island, Japan)

\begin{tabular}{|lccc|} 
& \multicolumn{3}{c|}{ Lithium levels } \\
\cline { 2 - 4 } Model & $\beta$ & $P$ & Adjusted $R^{2}$ \\
Crude model & -0.100 & 0.100 & 0.006 \\
Adjusted model & -0.106 & 0.016 & 0.482 \\
Adjusted for: & & & \\
$\quad$ Proportion of 1-person households & 0.442 & 0.000 & \\
$\quad$ Overall unemployment rate & 0.076 & 0.092 & \\
$\quad$ Proportion of elderly people & -0.387 & 0.000 & \\
\hline
\end{tabular}

association between lithium levels in tap water and mental health problems in a general population of adolescents using a large individual-level data-set in Japan between 2008 and 2009. They found an inverse association between lithium levels (mean $0.48 \mu \mathrm{g} / \mathrm{L}$; s.d. $=0.52$; range $0.01-2.10)$ and both symptoms of depression $(P=0.02)$ and interpersonal violence $(P=0.02)$.

Unlike the Texas study, ${ }^{5}$ in our study we used lithium levels as a continuous value, to exclude the possibility of spurious findings resulting from the arbitrary division of the levels. We found that lithium levels were significantly and inversely associated with crime rates across the 274 municipalities in Kyushu Island in the adjusted model.

\section{Limitations and further research}

This study has several limitations. The first is methodological problems. Although we used multiple regression analyses, it is necessary to consider whether an alternative statistical method (such as nonlinear model) would be more appropriate in future analyses. Second, we did not gather data on lithium intake from food, which generally exceeds that from drinking water. ${ }^{27}$ Goldstein \& Mascitelli ${ }^{27}$ suggested that, to ensure adequate daily dietary intake of lithium for the purpose of decreasing violence and aggression, nations should consider fortifying cereal grain products with lithium and adding lithium to vitamin preparations for adults. Third, bipolar disorder is deeply linked to impulsive crime. We should investigate whether the effects on crime of lithium in drinking water might be extrapolated from results on bipolar disorder. Regrettably, we could not obtain prevalence data on bipolar disorder 
in the different municipalities in Japan. However, in a nationwide Danish study, Kessing et al ${ }^{28}$ reported that the median of the average lithium exposure did not differ between individuals with mania/bipolar disorder $(12.7 \mu \mathrm{g} / \mathrm{L}$; interquartile range IQR $=7.9-$ $15.5 \mu \mathrm{g} / \mathrm{L})$ and age- and gender-matched controls $(12.5 \mu \mathrm{g} / \mathrm{L}$; IQR $=7.6-15.7 \mu \mathrm{g} / \mathrm{L} ; P=0.2)$ and that the incidence rate ratio of mania/bipolar disorder did not decrease with higher long-term lithium exposure overall or within age groups $(0-40,41-60$ and 61-100 years of age). Therefore, lithium intake from drinking water may be not associated with the incidence rate of bipolar disorder. Finally, we did not collect data on the study population's consumption of mineral water. In a previous study, we found that lithium levels in foreign mineral waters were significantly higher than those in Japanese mineral waters and tap water, although there was no significant difference between Japanese mineral waters and tap water. ${ }^{29}$ Future studies might consider what types of mineral water participants drink, to allow adjustment of the analytical data on the potential effect of lithium on crime. Further studies are also required to confirm the findings presented in this paper and to investigate gender differences in the suggested association between lithium in drinking water and crime rates.

Kentaro Kohno, MD, PhD, Department of Neuropsychiatry, Faculty of Medicine, Oita University, Yufu City, Japan; Nobuyoshi Ishii (D), MD, PhD, Department of Neuropsychiatry, Faculty of Medicine, Oita University, Yufu City, Japan;

Hirofumi Hirakawa, MD, Department of Neuropsychiatry, Faculty of Medicine, Oita University, Yufu City, Japan; Takeshi Terao (1D, MD, PhD, Department of

Neuropsychiatry, Faculty of Medicine, Oita University, Yufu City, Japan

Correspondence: Nobuyoshi Ishii. Email: nobuy@oita-u.ac.jp

First received 7 Feb 2020, final revision 23 Mar 2020, accepted 30 Jun 2020

\section{Data availability}

Authors have access to the original study data.

\section{Author contributions}

K.K. was responsible for the design of the study, acquisition and analysis of the data and writeup of the study. N.I. and H.H. was involved with collecting data. T.T. was responsible for the conception and design of the work and the critical revision of the study write-up.

\section{Declaration of interest}

None

CMJE forms are in the supplementary material, available online at https://doi.org/10.1192/ bjo. 2020.63 .

\section{References}

1 Schrauzer GN. Lithium: occurrence, dietary intakes, nutritional essentiality. J Am Coll Nutr 2002; 21: 14-21.

2 Ishii N, Terao T. Trace lithium and mental health. J Neural Transm 2018; 125 223-7.

3 Cipriani A, Hawton K, Stockton S, Geddes JR. Lithium in the prevention of suicide in mood disorders: updated systematic review and meta-analysis. BMJ 2013; 346: f3646

4 Matsunaga $\mathrm{S}$, Kishi T, Annas $\mathrm{P}$, Basun $\mathrm{H}$, Hampel $\mathrm{H}$, Iwata $\mathrm{N}$. Lithium as a treatment for Alzheimer's disease: a systematic review and meta-analysis. J Alzheimers Dis 2015; 48: 403-10.

5 Jones RM, Arlidge J, Gillham R, Reagu S, van den Bree M, Taylor PJ. Efficacy of mood stabilisers in the treatment of impulsive or repetitive aggression: systematic review and meta-analysis. Br J Psychiatry 2011; 198: 93-8.

6 Schrauzer GN, Shrestha KP. Lithium in drinking water and the incidences of crimes, suicides, and arrests related to drug addictions. Biol Trace Elem Res 1990; 25: 105-13.
7 Ohgami H, Terao T, Shiotsuki I, Ishii N, Iwata N. Lithium levels in drinking water and risk of suicide. Br J Psychiatry 2009; 194: 464-5.

8 Ishii N, Terao T, Araki Y, Kohno K, Mizokami Y, Shiotsuki I, et al. Low risk of male suicide and lithium in drinking water. J Clin Psychiatry 2015; 76: 319-26.

9 Knudsen NN, Schullehner J, Hansen B, Jorgensen LF, Kristiansen SM, Voutchkova DD, et al. Lithium in drinking water and incidence of suicide: a nationwide individual-level cohort study with 22 years of follow-up. Int $J$ Environ Res Public Health 2017; 14(6): 627.

10 BlumI V, Regier MD, Hlavin G, Rockett IR, Konig F, Vyssoki B, et al. Lithium in the public water supply and suicide mortality in Texas. J Psychiatr Res 2013; 47: 407-11.

11 Kessing LV, Gerds TA, Knudsen NN, Jorgensen LF, Kristiansen SM, Voutchkova $D$, et al. Association of lithium in drinking water with the incidence of dementia. JAMA Psychiatry 2017; 74: 1005-10.

12 Nunes MA, Viel TA, Buck HS. Microdose lithium treatment stabilized cognitive impairment in patients with Alzheimer's disease. Curr Alzheimer Res 2013; 10 $104-7$

13 Matsuzaki H, Terao T, Inoue T, Takaesu Y, Ishii N, Kohno K, et al. Re-analysis of the association of temperature or sunshine with hyperthymic temperament using lithium levels of drinking water. J Affect Disord 2017; 223: 126-9.

14 Ishii N, Terao T, Matsuzaki H, Inoue T, Takaesu Y, Kohno K, et al. Lithium in drinking water may be negatively associated with depressive temperament in the nonclinical population. CNPT 2017; 8: 7-11.

15 Dawson EB, Moore TD, McGanity WJ. Relationship of lithium metabolism to mental hospital admission and homicide. Dis Nerv Syst 1972; 33: 546-56.

16 Schrauzer GN, Shrestha KP, Flores-Arce MF. Lithium in scalp hair of adults, students, and violent criminals. Effects of supplementation and evidence for interactions of lithium with vitamin B12 and with other trace elements. Biol Trace Elem Res 1992: 34: 161-76.

17 Giotakos O, Tsouvelas G, Nisianakis P, Giakalou V, Lavdas A, Tsiamitas C, et al . A negative association between lithium in drinking water and the incidences of homicides, in Greece. Biol Trace Elem Res 2015; 164: 165-8.

18 Sampson RJ, Laub JH, Wimer C. Does marriage reduce crime? A counterfactual approach to within-individual causal effects. Criminology 2006; 44: 465-508.

19 Webster C, Kingston S. Poverty and Crime. Joseph Rowntree Foundation, 2014.

20 Rocque, M, Posick C, Hoyle, J. Age and crime. The Encyclopedia of Crime and Punishment (ed WG Jennings): 1-8. Wiley Online Library, 2015.

21 The Statistics Bureau. Statistical Observations of Municipalities. Ministry of Internal Affairs and Communications Japan, 2010 (https://www.e-stat.go.jp/ stat-search?page=1\&query=\%E5\%B8\%82\%E5\%8C\%BA\%E7\%94\%BA\%E6\%9D \%91\%E3\%81\%AE\%E3\%81\%99\%E3\%81\%8C\%E3\%81\%9F\%E3\%80\%802010\& layout=dataset $\&$ metadata $=1 \&$ data $=1$ )

22 Babinski LM, Hartsough CS, Lambert NM. Childhood conduct problems, hyperactivity-impulsivity, and inattention as predictors of adult criminal activity. J Child Psychol Psychiatry 1999; 40: 347-55.

23 Ohmura Y, Tsutsui-Kimura I, Kumamoto H, Minami M, Izumi T, Yamaguchi T, et al. Lithium, but not valproic acid or carbamazepine, suppresses impulsivelike action in rats. Psychopharmacology 2012; 219: 421-32.

24 Halcomb ME, Gould TD, Grahame NJ. Lithium, but not valproate, reduces impulsive choice in the delay-discounting task in mice. Neuropsychopharmacology 2013; 38: 1937-44.

25 Hollander E, Pallanti S, Allen A, Sood E, Baldini Rossi N. Does sustained-release lithium reduce impulsive gambling and affective instability versus placebo in pathological gamblers with bipolar spectrum disorders? Am J Psychiatry 2005: 162: 137-45.

26 Ando S, Koike S, Shimodera S, Fujito R, Sawada K, Terao T, et al. Lithium levels in tap water and the mental health problems of adolescents: an individual-level cross-sectional survey. J Clin Psychiatry 2017; 78: e252-6.

27 Goldstein MR, Mascitelli L. Is violence in part a lithium deficiency state? Med Hypotheses 2016; 89: 40-2.

28 Kessing LV, Gerds TA, Knudsen NN, Jørgensen LF, Kristiansen SM, Voutchkova D, et al. Lithium in drinking water and the incidence of bipolar disorder: a nationwide population-based study. Bipolar Disord 2017; 19: 563-7.

29 Ishii N, Terao T, Shiotsuki I, Kanehisa M. Comparison of lithium levels between Japanese and foreign mineral waters. CNPT 2017; 8: 13-5. 